\title{
Diabetes in the older patient: heterogeneity requires individualisation of therapeutic strategies
}

\author{
Guntram Schernthaner $^{1}$ • Marie Helene Schernthaner-Reiter ${ }^{2}$
}

Received: 30 August 2017 / Accepted: 29 November 2017 / Published online: 7 February 2018

(C) The Author(s) 2018. This article is an open access publication

\begin{abstract}
Owing to the worldwide increase in life expectancy, the high incidence of diabetes in older individuals and the improved survival of people with diabetes, about one-third of all individuals with diabetes are now older than 65 years. Evidence is accumulating that type 2 diabetes is associated with cognitive impairment, dementia and frailty. Older people with diabetes have significantly more comorbidities, such as myocardial infarction, stroke, peripheral arterial disease and renal impairment, compared with those without diabetes. However, as a consequence of the increased use of multifactorial risk factor intervention, a considerable number of older individuals can now survive for many years without any vascular complications. Given the heterogeneity of older individuals with type 2 diabetes, an individualised approach is warranted, which must take into account the health status, presence or absence of complications, and life expectancy. In doing so, undertreatment of otherwise healthy older individuals and overtreatment of those who are frail may be avoided. Specifically, overtreatment of hyperglycaemia in older patients is potentially harmful; in particular, insulin and sulfonylureas should be avoided or, if necessary, used with caution. Instead, glucose-dependent drugs that do not induce hypoglycaemia are preferable since older patients with diabetes and impaired kidney function are especially vulnerable to this adverse event.
\end{abstract}

Keywords Age $\cdot$ Chronic kidney disease $\cdot$ Frailty $\cdot$ Glycaemic target $\cdot$ Hypoglycaemia $\cdot$ Older people $\cdot$ Review $\cdot$ Type 2 diabetes mellitus

\section{Abbreviations \\ CKD Chronic kidney disease \\ CVD Cardiovascular disease \\ DPP-4 Dipeptidyl peptidase-4 \\ ESRD End-stage renal disease \\ FDA Food and Drug Administration \\ GLP-1 Glucagon-like peptide-1}

Electronic supplementary material The online version of this article (https://doi.org/10.1007/s00125-018-4547-9) contains peer-reviewed but unedited supplementary material including a slide of the figure for download, which is available to authorised users.

Guntram Schernthaner

guntram.schernthaner@meduniwien.ac.at

$\bowtie$ Marie Helene Schernthaner-Reiter

marie.schernthaner-reiter@meduniwien.ac.at

1 Department of Medicine 1, Rudolfstiftung Hospital, Juchgasse 25, 1030 Vienna, Austria

2 Clinical Division of Endocrinology and Metabolism, Department of Internal Medicine III, Medical University of Vienna, Währinger Gürtel, 18-20 1090 Vienna, Austria
IDF International Diabetes Federation

MACE Major adverse cardiovascular event

SGLT-2 Sodium-glucose cotransporter-2

TIA Transient ischaemic attack

\section{Introduction}

In recent decades worldwide rates of diabetes have been on the rise, especially among older people. The global prevalence of diabetes is estimated to increase to 642 million by 2040 and the largest age-specific rise is predicted to be among people aged between 60 and 79 years [1]. Currently, approximately $20 \%$ of people between 70 and 79 years are thought to have diabetes [1]. The ageing of the population is thought to be one of the most important contributors to the prevalence of diabetes, since increasing age is a substantial risk factor for the development of this disease [1]. In the USA, more than onethird of the adult population with diabetes is currently aged 65 years or older, comprising almost 11 million people [2]. A very high prevalence of type 2 diabetes in older individuals is 
seen not only in the Western world, where economic standards are high, but also in developing countries, such as Brazil [3] and China [4]. In Brazil, almost 3 million of the 12 million people with diabetes are older than 65 years [3], whereas, in China, 35 million of the 92 million people with diabetes are older than 60 years and 20 million are older than 70 years [4].

In this article, we review the literature on diabetes in older people. We initially preselected about 500 papers in PubMed using the search terms 'diabetes and age', 'ageing in diabetic patients', 'treatment of elderly patients' and 'co-morbidity of elderly patients'. Finally, about 100 references were used; RCTs and recent publications in high-ranking journals were preferred.

\section{Pathophysiology and types of diabetes in older people}

The vast majority of older adults with diabetes have type 2 diabetes ( $>90 \%)$, owing to a combination of increased insulin resistance and impaired insulin secretion. Insulin resistance that is associated with advancing age is believed to be due to a combination of adiposity, sarcopenia (decreased muscle mass) and physical inactivity [5]. Impaired pancreatic beta cell adaptation to insulin resistance appears to be an important contributing factor to age-related glucose intolerance and risk of diabetes [6].

The identification of individuals with latent autoimmune diabetes of adults (LADA) is relevant for therapeutic decisions [7], since these individuals need insulin therapy much earlier than those with classical type 2 diabetes. Furthermore, since the longevity of people with childhood autoimmune diabetes has improved considerably over recent decades [8], an increasing proportion of older individuals with diabetes are those with classical type 1 diabetes.

\section{Comorbidities in older people with diabetes}

The population of older people with type 2 diabetes consists of a spectrum of different disease severities between two extremes: those with long-standing type 2 diabetes since middle age and those with incident type 2 diabetes that only develops in older age. There are clear differences in the comorbidities and ease of glycaemic control in these two different type 2 diabetes categories, underlining that one-size-fits-all treatment guidelines are not appropriate in this age group.

Vascular complications If well treated for all cardiovascular risk factors from the time of diagnosis of diabetes, a considerable number of older people with diabetes remain free from severe vascular complications and can survive for many years [9]. By contrast, those who have not been well treated over an extended period can develop a range of macrovascular and microvascular complications. In the prospective GERODIAB observational study ( $n=997$ participants with type 2 diabetes; median age, 77 years old), the frequencies of all cardiovascular complications increased from $47 \%$ to $67 \%$ during the 5 year follow-up, including CHD, peripheral vascular disease and cerebrovascular disease [10]. Heart failure more than doubled during follow-up (9\% to $20 \%$ ) and was the strongest predictor of poor survival. Amputation and foot wounds were also strongly associated with poor survival [10].

Cognitive impairment and dementia Evidence is accumulating that type 2 diabetes is associated with cognitive impairment and dementia. Numerous epidemiological studies have demonstrated that people with type 2 diabetes have a significantly higher risk of developing Alzheimer's disease [11, 12]. Dementia affects up to $16 \%$ of individuals with diabetes aged $>65$ and $24 \%$ aged $>75$ [13], and evidence shows that diabetes and dementia share a pathophysiological link [12]. Higher glucose levels were found to be associated with an increased risk of dementia in populations with and without diabetes [14], with this association being stronger in those with diabetes. Moreover, insulin resistance is also an important risk factor for cognitive impairment in older people with type 2 diabetes [15]. On the other hand, however, prospective studies have shown that severe hypoglycaemia is also a risk factor for cognitive impairment and dementia [16, 17]. Since cognitive dysfunction affects treatment adherence and diabetes selfmanagement, the resulting poor glycaemic control and an increased rate of severe hypoglycaemia contribute to a vicious cycle. Overall, individuals with cognitive dysfunction have difficulty performing self-care (e.g. matching insulin dosage to carbohydrate intake or avoiding and treating hypoglycaemia), leading to a significantly reduced quality of life [18].

Frailty Frailty is a state of increased vulnerability to minor stressors, leading to difficulties in maintenance of homoeostasis, which increases the risk of adverse outcomes (disability, falls and death). When frailty occurs in older people with diabetes, sarcopenia or loss of muscle mass seems to be accelerated. In the Canadian Study of Health and Aging [19], the median life expectancy of frail older adults with diabetes was only 23 months. Recent studies suggest that crosstalk between insulin resistance, adipose tissue inflammation and skeletal muscle inflammation and dysfunction is involved in the development of sarcopenia and frailty [20]. Poor glycaemic control should be avoided, since in the Cardiovascular Health Study, an $\mathrm{HbA}_{1 \mathrm{c}} \geq 63.9 \mathrm{mmol} / \mathrm{mol}$ $(\geq 8.0 \%$ ) (vs $<36.6 \mathrm{mmol} / \mathrm{mol}[<5.5 \%])$ was associated with a threefold increased risk of incident frailty and a three- to fivefold increased risk of lower extremity mobility limitations [21]. Frailty is also strongly associated with the presence of 
chronic kidney disease (CKD); it occurs in $21 \%$ of those with an eGFR $<45 \mathrm{ml} \mathrm{min}^{-1}[1.73 \mathrm{~m}]^{-2}$ [22]. The appearance of frailty can change the natural history of type 2 diabetes, from a progressive to a regressive course with increased risk of hypoglycaemia [23]; declining body function associated with weight loss and malnutrition may lead to normoglycaemia and an increased risk of hypoglycaemia. In this situation it is important to reduce any hypoglycaemic medication or even withdraw it when necessary.

\section{Glycaemic control to reduce mortality rates in older people with type 2 diabetes}

In the last 20 years, rates of all diabetes-associated vascular complications [24], as well as all-cause and cardiovascular mortality [25-28], have declined significantly in countries with high medical and economic standards, most likely because polypharmacy has reduced cardiovascular risk factors such as hypertension and dyslipidaemia. As a result of the considerably improved prognosis and longer survival of people with type 2 diabetes, in the future we will be confronted by a much higher proportion of older patients. The risk associated with diabetes and its comorbidities is well illustrated by two large studies of populations with very different socioeconomic backgrounds: a recent nationwide study from Sweden showing the 5 year follow-up of 450,000 older people with type 2 diabetes [9] and a prospective 12 year study from Mexico City that included $>19,000$ people with type 2 diabetes [29] (summarised in Table 1). In contrast to the Swedish study, where encouragingly the excess mortality owing to diabetes was low, a very different picture emerged in Mexico City, with a high excess mortality rate, worse glycaemic control and much lower rates of antihypertensive and lipid-lowering medication (Table 1). These findings highlight the importance of adequate glycaemic control in combination with good control of cardiovascular risk factors. Interestingly, the data from Mexico City showed a much higher excess mortality from renal disease than from cardiovascular disease (CVD) in study participants.

Figure 1 shows the adjusted HRs for all-cause mortality (Fig. 1a) and cardiovascular death (Fig. 1b) in individuals with diabetes in the Swedish study vs control participants, in relation to $\mathrm{HbA}_{1 \mathrm{c}}$ level and age [9]. All-cause mortality and cardiovascular death were related to $\mathrm{HbA}_{1 \mathrm{c}}$ in all age groups but were much more pronounced in younger people ( $<55$ years of age). In those older than 75 years, the adjusted HR for all-cause mortality and cardiovascular death was only 1.5 and 1.4 , respectively, in those with an $\mathrm{HbA}_{1 \mathrm{c}} \geq 82.5 \mathrm{mmol} / \mathrm{mol}(\geq 9.7 \%)$, and 1.20 and 1.15, respectively, in those with an $\mathrm{HbA}_{1 \mathrm{c}}$ of $62.8-$
$71.6 \mathrm{mmol} / \mathrm{mol}$ (7.9-8.7\%). Remarkably, participants between 65 and 74 years of age without albuminuria and with an $\mathrm{HbA}_{1 \mathrm{c}} \leq 51.9 \mathrm{mmol} / \mathrm{mol}(\leq 6.9 \%)$ had a lower risk in terms of all-cause mortality compared with control participants; the risk was also lower among participants $\geq 75$ years with an $\mathrm{HbA}_{1 \mathrm{c}} \leq 61.7 \mathrm{mmol} / \mathrm{mol}(\leq 7.8 \%)$ than among control participants.

\section{Overtreatment and undertreatment of older patients with type 2 diabetes}

In older adults with diabetes and multiple serious comorbidities and functional limitations, the harm of intensive glycaemic control likely exceeds the benefits. Among people $\geq 65$ years old, glucose-lowering agents with a risk of hypoglycaemia (insulin and sulfonylureas) were the second most common medications associated with emergency department visits or hospitalisations [30] reported to the US Food and Drug Administration (FDA). The frequent overtreatment of older patients with diabetes, or those with complex comorbidities, has been well documented. Many studies showed that older patients and/or patients with complex or poor health were under tight glycaemic control (often aiming for $\mathrm{HbA}_{1 \mathrm{c}}$ $<53.0 \mathrm{mmol} / \mathrm{mol}[<7.0 \%]$ ) and a large proportion received medication associated with hypoglycaemia (sulfonylureas or insulin) [31-33]. This is especially problematic in older patients with dementia who are at much greater risk of hypoglycaemia compared with those without dementia [34] and may be at an added risk of drug interactions due to polypharmacy [35].

In patients with high clinical complexity, intensive treatment significantly increased the risk-adjusted probability of severe hypoglycaemia [36] from $1.74 \%$ with standard treatment to $3.04 \%$ with intensive treatment. Given the heterogeneity of older patients with type 2 diabetes, an individualised approach is warranted to avoid overtreatment of frail older individuals and undertreatment of those who are otherwise healthy, as recently observed in a large Canadian observational study [33]. In this study, more than half of those with high clinical complexity had $\mathrm{HbA}_{1 \mathrm{c}}$ levels $\leq 53 \mathrm{mmol} / \mathrm{mol}(\leq 7.0 \%)$, whereas, in those with $\mathrm{HbA}_{1 \mathrm{c}}$ levels $\geq 53 \mathrm{mmol} / \mathrm{mol}(\geq 7.0 \%)$ and low clinical complexity, there was often no up-titration or initiation of additional antihyperglycaemic agents [33].

High risk of severe hypoglycaemia in older people with type 2 diabetes and comorbidities Hypoglycaemia is the key ratelimiting step for optimising glycaemic control. It is more common in older individuals with diabetes because of impaired renal and hepatic metabolism with slower counterregulatory mechanisms, polypharmacy or nonadherence to medications, as well as erratic or poor food 
Table 1 Risk associated with diabetes and its comorbidities (Sweden vs Mexico City)

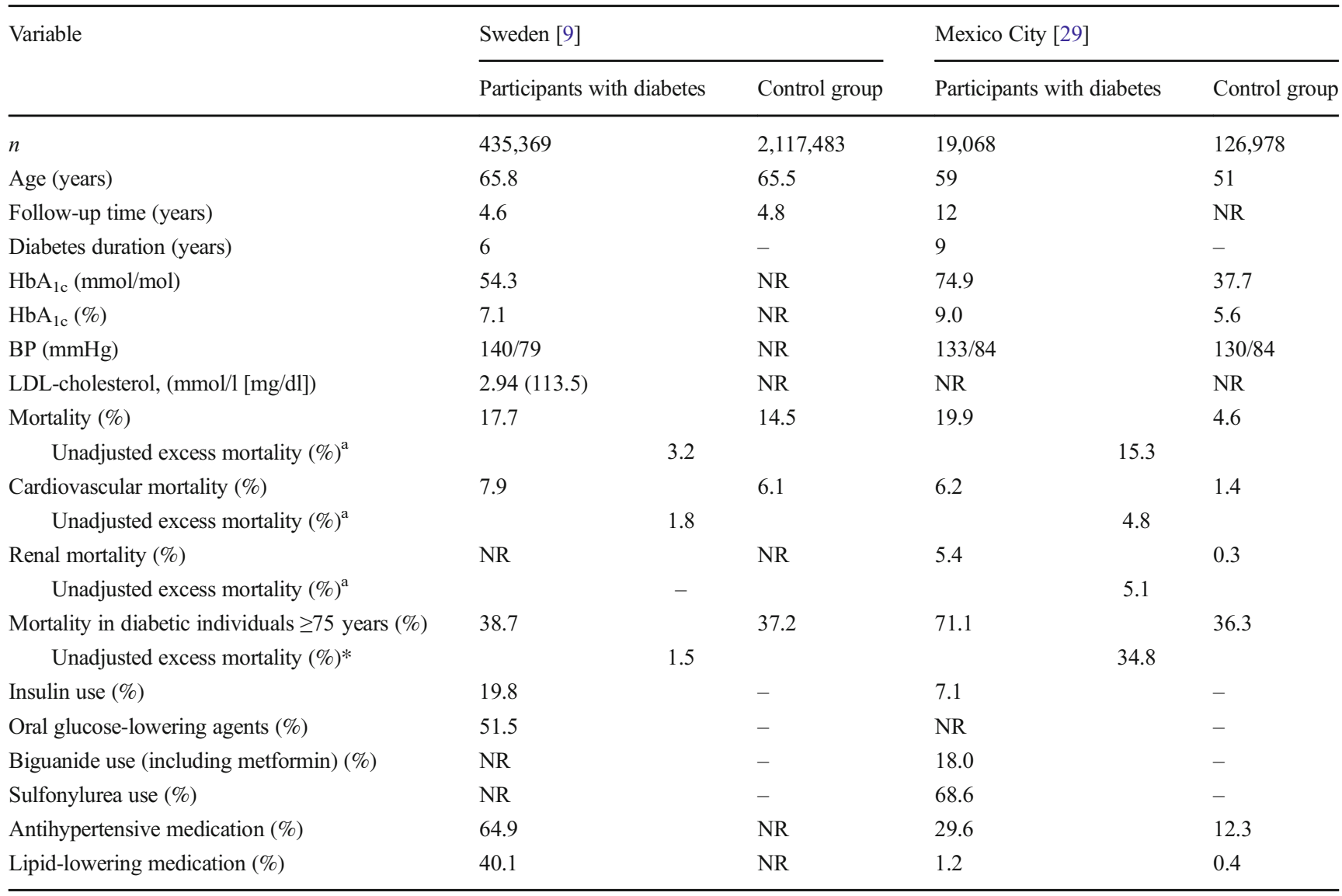

${ }^{\mathrm{a}}$ Unadjusted excess mortality was calculated as the difference in percentage mortality between control and diabetes groups NR, not reported

intake. Since older people with type 2 diabetes exhibit higher complexity, in part due to the higher rate of

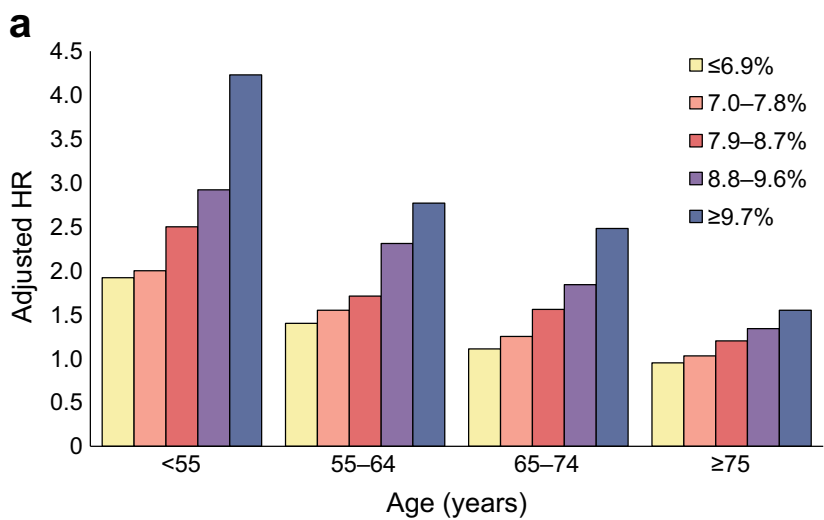

Fig. 1 Death from (a) any cause and (b) from a cardiovascular cause in participants with type 2 diabetes vs control participants. Data shows findings from the Swedish National Diabetes Register [9]. Mean $\mathrm{HbA}_{1 \mathrm{c}}$ levels are indicated as follows: yellow bars, $<51.9 \mathrm{mmol} / \mathrm{mol}(\leq 6.9 \%)$; pink bars, $53.0-61.5 \mathrm{mmol} / \mathrm{mol}(7.0-7.8 \%)$; red bars, $60.7-71.6 \mathrm{mmol} / \mathrm{mol}$ (7.9-8.7\%); purple bars, $72.7-81.4 \mathrm{mmol} / \mathrm{mol}(8.8-9.6 \%)$; blue bars, comorbidities, individualisation of glycaemic targets and treatment strategies is warranted to avoid harm and

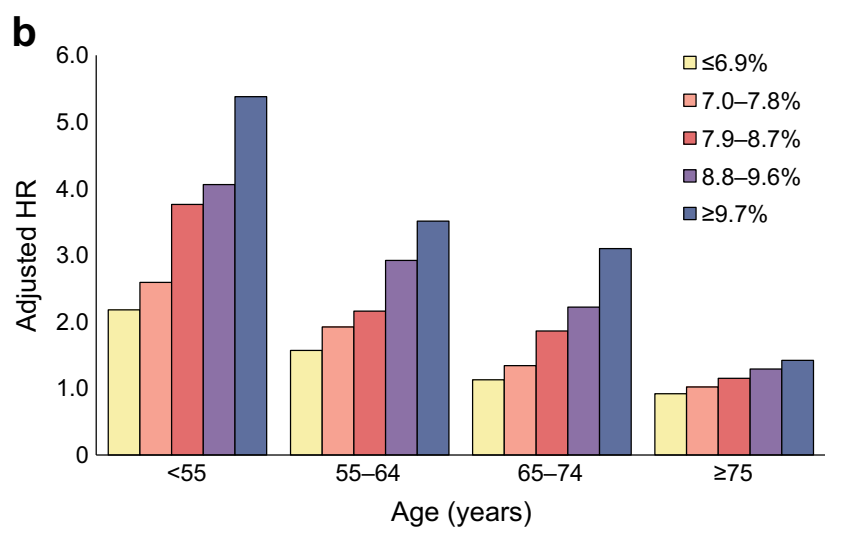

$>82.5 \mathrm{mmol} / \mathrm{mol}(\geq 9.7 \%)$. Overall, 77,117 of 435,369 participants with type 2 diabetes (17.7\%) died from any cause, as compared with 306,097 of 2,117,483 control participants (14.5\%) (adjusted HR 1.15 [95\% CI $1.14,1.16])$. $p$ values for the interaction term between time-updated mean $\mathrm{HbA}_{1 \mathrm{c}}$ or renal disease status and time-updated age categories were $<0.001$ in all models. This figure is available as a downloadable slide 
maximise benefits [37-39]. The recently published trends from 2006 to 2013 [40] in drug use, glycaemic control and rates of severe hypoglycaemia in large cohorts of individuals with diabetes in the USA provide clinically relevant information. Out of the 700,000 individuals analysed in 2013, 50.8\% were older than 65 years and $22 \%$ were older than 75 years. Rates of severe hypoglycaemia were significantly higher among the oldest compared with the younger individuals (events per 100 person-years: $>75$ years, $2.3 ; 65-74$ years, $1.3 ;<65$ years, $0.9)$, and rates of severe hypoglycaemia were particularly high among individuals with two or more comorbidities (3.5 events per 100 person-years) compared with those with no comorbidities ( 0.4 events per 100 person-years).

There is increasing epidemiological evidence that severe hypoglycaemia may be associated with an increased risk of CVD among people with type 2 diabetes. In a recent very large retrospective cohort study of 58,000 Japanese individuals with diabetes [41], severe hypoglycaemia was strongly associated with the risk of CVD (multivariate-adjusted HR 3.39). Older age (HR 1.24 [95\% CI 1.02, 1.52]), long duration of diabetes (HR 1.58 [95\% CI 1.14, 2.20]) and a higher Charlson Comorbidity Index (HR 1.14 [95\% CI 1.05, 1.23]) were predictors for the development of severe hypoglycaemia, but the strongest predictor was the use of insulin (HR 7.05 [95\% CI 4.68, 10.60]). A study using continuous glucose monitoring in older individuals ( $>69$ years) with poor glycaemic control $\left(\mathrm{HbA}_{1 \mathrm{c}}>63.9 \mathrm{mmol} / \mathrm{mol}[>8.0 \%]\right)$ found an unexpectedly high frequency of hypoglycaemic episodes $(<2.8 \mathrm{mmol} / 1[50 \mathrm{mg} / \mathrm{dl}])$ in almost half [42]. Based on their findings, the authors concluded that simply relaxing $\mathrm{HbA}_{1 \mathrm{c}}$ goals may not be sufficient to protect frail older adults against hypoglycaemia. Especially in the light of an association between hypoglycaemia and CVD, many older people with diabetes who use insulin and/or sulfonylureas may benefit from a switch to antihyperglycaemic regimens including drugs that do not induce hypoglycaemia, such as metformin, dipeptidyl peptidase-4 (DPP-4) inhibitors, sodium-glucose cotransporter-2 (SGLT-2) inhibitors, pioglitazone or glucagon-like peptide-1 (GLP-1) receptor agonists.

\section{Renal impairment is common in older people with type 2 diabetes}

CKD is a frequent finding in older people with type 2 diabetes [43] and needs to be detected and followed up for selection of the appropriate glucose-lowering drug and dose adaptation when progression of renal impairment occurs $[44,45]$. In a retrospective analysis of a large cohort $(n=71,092$, enrolled in the Kaiser Permanente Northern California Diabetes Registry) of older people with type 2 diabetes, CKD stage 3 (eGFR 30$59 \mathrm{ml} \mathrm{min}^{-1}[1.73 \mathrm{~m}]^{-2}$ ) was found in $32 \%$ and CKD stage 4
(eGFR $15-30 \mathrm{ml} \mathrm{min}^{-1}[1.73 \mathrm{~m}]^{-2}$ ) in $2.6 \%$ of participants [43]. Owing to the decline in cardiovascular death in older people in recent years, more of those with type 2 diabetes and CKD, in particular those presenting with macroalbuminuria, will be at high risk of developing endstage renal disease (ESRD). In the Action in Diabetes and Vascular Disease: Preterax and Diamicron Modified Release Controlled Evaluation (ADVANCE) study, intensive glucose control with insulin and gliclazide [46] significantly reduced the risk of ESRD by $65 \%$ (the number needed to treat was only 41), but increased the risk of severe hypoglycaemia, which was associated with an increase in cardiovascular death [47].

Clemens et al [48] recently reported on the prescriptions of glucose-lowering medication in a large population-based study (Ontario, Canada) of 144,252 older adults (mean age, 78 years) with diabetes and CKD, including individuals on dialysis. Although there were trends towards prescription of safer antihyperglycaemic medication in patients with CKD between 2004 and 2013, up to 49\% of those with CKD stages $3-5$ and those receiving chronic dialysis were prescribed glibenclamide (known as glyburide in the USA and Canada), and up to $28 \%$ with CKD stages $4-5$ and those receiving chronic dialysis were prescribed metformin. Although the use of metformin has a beneficial effect in patients with type 2 diabetes and moderate CKD [49], it should not be prescribed in those with severe renal impairment, since a dose-dependent mortality was observed when metformin was used in individuals with CKD stage 5 [50]. In a recent population-based study [51] of $>120,000$ individuals with diabetes who were new users of a non-insulin glucose-lowering agent, individuals with an eGFR $<30 \mathrm{ml} \mathrm{m^{-1 }}[1.73 \mathrm{~m}]^{-2}$ using only sulfonylureas had a fivefold increased risk of hypoglycaemia compared with users of metformin only (HR 4.96 [95\% CI 3.76, 6.55]). As a result of the very high risk of hypoglycaemia, sulfonylureas should not be used in older patients with impaired renal function. In particular, glibenclamide should be completely avoided, since the associated risk of hypoglycaemia was found to be extremely high (HR 7.48). Individuals with diabetes now have an improved life expectancy but with this comes a longer duration of the disease and its complications, which translates into a greater need for the use of multiple safe agents to maintain glycaemic control. Currently, safer glucose-dependent glycaemic control with DPP-4 inhibitors may be the best choice of treatment in those with diabetes with impaired kidney function [52].

\section{Treatment targets in older patients with diabetes}

There is substantial uncertainty about optimal glycaemic control in older adults with type 2 diabetes mellitus. Until 2010, 
guidelines recommended $\mathrm{HbA}_{1 \mathrm{c}}$ targets below $53 \mathrm{mmol} / \mathrm{mol}$ $(7.0 \%)$ or $47.5 \mathrm{mmol} / \mathrm{mol}(6.5 \%)$ without any reference to specific glucose-lowering treatments, patient age, diabetes duration or pre-existing CVD [53]. Studies evaluating the effect of intensive glucose lowering (Action to Control Cardiovascular Risk in Diabetes [ACCORD], ADVANCE and Veterans Affairs Diabetes Trial [VADT]) failed to demonstrate a reduction in all-cause mortality and cardiovascular mortality [54-56]. The high frequency of severe hypoglycaemia in these studies was related to the percentage of participants using insulin in the intervention arms [57] and was associated with higher mortality rates [47, 58]. Based on the results of these three landmark studies, Ismail-Beigi et al [38] and the ADA/EASD consensus group [39] proposed individualising glycaemic targets in type 2 diabetes according to the presence or absence of vascular complications, patient age and duration of disease.

In recent years, several international expert groups (the European Diabetes Working Party for Older People, the ADA, the International Diabetes Federation [IDF] and Diabetes Canada (formerly the Canadian Diabetes Association) have provided consensus statements and detailed guidance on the management of diabetes in older people [35, 59-62]. Most of the recommendations are relatively similar; the targets for $\mathrm{HbA}_{1 \mathrm{c}}$, BP and LDL-cholesterol levels according to functional status in older people with type 2 diabetes as proposed by the ADA, IDF and Diabetes Canada are summarised in Table 2.

Recent results from the National Health and Nutrition Examination Surveys (NHANES) suggest that poorly controlled diabetes is associated with worse outcomes, including in older people. After a follow-up of 8.9 years, an $\mathrm{HbA}_{1 \mathrm{c}}$ $>63.9 \mathrm{mmol} / \mathrm{mol}(>8.0 \%)$ was associated with an increased risk of all-cause and cause-specific mortality in older adults with diabetes [63]. In a UK population-based cohort study
[64], $>25,000$ individuals with type 2 diabetes in the age range of 80 to 89 years were followed-up for a median of 2 years; $35 \%$ had a previous diagnosis of CHD, while $11 \%$ had previously suffered a stroke. A U-shaped relationship between $\mathrm{HbA}_{1 \mathrm{c}}$ and mortality was observed, with the lowest mortality in people with a baseline $\mathrm{HbA}_{1 \mathrm{c}}$ of $53 \mathrm{mmol} / \mathrm{mol}(7.0 \%)$ to $57 \mathrm{mmol} / \mathrm{mol}(7.4 \%)$, whereas mortality in those with low $(<42 \mathrm{mmol} / \mathrm{mol}[<6.0 \%])$ or high $(\geq 69 \mathrm{mmol} / \mathrm{mol}[\geq 8.5 \%])$ $\mathrm{HbA}_{1 \mathrm{c}}$ values was significantly higher.

A multifactorial intervention strategy aiming to reduce all cardiovascular risk factors is now generally recommended to reduce the burden of macrovascular and microvascular complications in people with type 2 diabetes. BP targets are still controversial, in particular concerning protection against stroke and progression of kidney disease. Recently, the ADA and EASD changed their recommended BP targets from $130 / 80 \mathrm{mmHg}$ to $140 / 90 \mathrm{mmHg}$ [65]. According to their recommendations, moderate BP control in older people with diabetes according to health status is an appropriate strategy for reducing vascular risk without causing harm. The ADA and EASD guidelines also recommend a target LDL-cholesterol of $2.59 \mathrm{mmol} / 1$ $(100 \mathrm{mg} / \mathrm{dl})$ for primary prevention and $1.81 \mathrm{mmol} / \mathrm{l}$ $(70 \mathrm{mg} / \mathrm{dl})$ for secondary prevention in high-risk individuals. For individuals with diabetes who are $>75$ years of age, there are limited data regarding the benefits and risks of statin therapy. In older patients with a limited life expectancy, any benefits of statins could be counterbalanced by the risks associated with age, polypharmacy, frailty and severe myalgia. Statin therapy should be individualised based on risk profile; for example, high-intensity statin therapy, if well tolerated, is still appropriate and recommended for older adults with manifest atherosclerotic vascular disease [66].

Table 2 Individualised targets for $\mathrm{HbA}_{1 \mathrm{c}}$, BP and LDL-cholesterol in older adults according to health status, proposed by the ADA, IDF and Diabetes Canada

\begin{tabular}{|c|c|c|c|c|c|c|}
\hline \multirow[t]{2}{*}{ Target } & \multicolumn{2}{|l|}{$\mathrm{ADA}$} & \multicolumn{2}{|l|}{ IDF } & \multicolumn{2}{|c|}{ Diabetes Canada } \\
\hline & Patient group & Target & Patient group & Target & $\begin{array}{l}\text { Patient } \\
\text { group }\end{array}$ & Target \\
\hline \multirow{3}{*}{$\begin{array}{l}\mathrm{HbA}_{1 \mathrm{c}} \\
\quad \mathrm{mmol} / \mathrm{mol}(\%)\end{array}$} & Healthy & $<58.5(7.5)$ & Functional/independent & $53.0-58.5(7.0-7.5)$ & Healthy & $\leq 53.0(7.0)$ \\
\hline & Complex/intermediate & $<63.9(8.0)$ & Functional/dependent & $53.0-63.9(7.0-8.0)$ & & \\
\hline & $\begin{array}{l}\text { Very complex/poor } \\
\text { health }\end{array}$ & $<69.4(8.5)$ & Frail & $<69.4(8.5)$ & Frail & $\leq 69.4(8.5)$ \\
\hline \multirow{3}{*}{$\begin{array}{l}\mathrm{BP}, \\
\mathrm{mmHg}\end{array}$} & Healthy & $<140 / 90$ & Functional/independent & $<140 / 90$ & & $<130 / 80$ \\
\hline & Complex/intermediate & $<140 / 90$ & & & & \\
\hline & $\begin{array}{l}\text { Very complex/poor } \\
\text { health }\end{array}$ & $<150 / 90$ & Frail & $<150 / 90$ & & \\
\hline $\begin{array}{l}\text { LDL-cholesterol, } \\
\mathrm{mmol} / 1(\mathrm{mg} / \mathrm{dl})\end{array}$ & & $\begin{array}{l}\text { Statins unless } \\
\text { contraindicated }\end{array}$ & & $<2.07(<80)$ & & $\leq 2.07(\leq 80)$ \\
\hline
\end{tabular}




\section{Individualisation of glucose-lowering therapy}

Metformin mono- and combined therapy Metformin is the leading glucose-lowering drug worldwide and is also the first-line oral medication for hyperglycaemia in older adults [67]. The rise, fall and revival of metformin in the therapy of type 2 diabetes is unique, changing its position from a devil in the 1970s to an angel in the last 20 years [68]. Metformin has been in clinical use for diabetes treatment for 60 years and all potential advantages and disadvantages are very well known [69]. The glucose-lowering effect is profound [70] and relatively long-lasting. Because metformin's mechanism of action predominantly involves a reduction in hepatic glucose production, it rarely causes hypoglycaemia when used alone [69]. Many properties, such as low costs, weight loss of $2-3 \mathrm{~kg}[70,71]$, antiatherogenic effects, as well as the option to be combined with all other drugs, explain why metformin is recommended in all guidelines as a first-line therapy. According to a recent large UK observational study [64], metformin was used in more than $60 \%$ of patients with diabetes aged between 80 and 89 years. Some older people may experience intolerable gastrointestinal discomfort and decreased appetite with metformin use. Further, as aforementioned, kidney function declines with age and some caution is needed since metformin is contraindicated in those with renal failure. The FDA advises against the use of metformin in patients with an eGFR of $<30 \mathrm{ml} \mathrm{min}^{-1}$ $[1.73 \mathrm{~m}]^{-2}$.

In a very large prospective study [71], the durability of the glucose-lowering effects of rosiglitazone, metformin or glibenclamide monotherapy was analysed in 4360 patients with a short duration of diabetes ( $<2$ years in $97 \%$ of the study group). The cumulative incidence of treatment failure of metformin (defined as fasting plasma glucose $>10.0 \mathrm{mmol} / 1$ [180 mg/dl]) after 5 years was $21 \%$ and, after 4 years, only $36 \%$ of those using metformin had an $\mathrm{HbA}_{1 \mathrm{c}}<53 \mathrm{mmol} / \mathrm{mol}$ $(<7.0 \%)$. In principle, all six classes of glucose-lowering drugs proposed by the ADA-EASD consensus statement [67] could be considered as second-line treatment in addition to metformin but, as stated above, in older patients with high comorbidity, drugs inducing hypoglycaemia may not be the best choice. Nonetheless, owing to the economic burden, sulfonylureas are still widely used, even in extremely elderly patients with complex type 2 diabetes. A relatively better choice, when the economic situation does not allow for the use of modern drugs, may be gliclazide, a sulfonylurea with the lowest risk of hypoglycaemia that may be safer than other compounds $[72,73]$.

DPP-4 inhibitors, SGLT-2 inhibitors and GLP-1 receptor agonists Experience with the use of newer glucose-lowering drugs (DPP-4 inhibitors, SGLT-2 inhibitors, GLP-1 receptor agonists) is increasing. Importantly, these drugs are not associated with an increased risk of hypoglycaemia [67]. DPP-4 inhibitors have been examined in several prospective RCTs in older patients with type 2 diabetes, and their efficacy, safety and very low risk of hypoglycaemia compared with sulfonylureas or placebo has been documented [74-76]. In the UK, since 2009, a significant trend towards fewer hospitalisations for hypoglycaemia was recently reported among older adults (65-80 years) with type 2 diabetes, which may be explained by the decreasing use of sulfonylureas [77]. Several large studies of DPP-4 inhibitors (Saxagliptin Assessment of Vascular Outcomes Recorded in Patients with Diabetes Mellitus [SAVOR], Examination of Cardiovascular Outcomes with Alogliptin versus Standard of Care [EXAMINE], Trial Evaluating Cardiovascular Outcomes with Sitagliptin [TECOS]) have not shown any cardiovascular benefit but have demonstrated safety [78-81]. However, some caution against the use of DPP-4 inhibitors in patients with heart failure is needed, in particular when renal impairment is present [82].

The baseline characteristics of participants in all 11 cardiovascular outcome trials in those with diabetes published up to now (October 2017) are summarised in electronic supplementary material (ESM) Table 1. Five out of the 11 trials investigated newer glucose-lowering drugs (pioglitazone, empagliflozin, liraglutide, semaglutide, canagliflozin) and demonstrated a significant reduction in three-point major adverse cardiovascular events (MACE; cardiovascular death, non-fatal myocardial infarction and non-fatal stroke), whereas six drugs (insulin glargine, saxagliptin, alogliptin, sitagliptin, lixisenatide and exenatide) showed safety but no change in cardiovascular mortality and morbidity when compared with placebo [78-80, 83-89]. Since the mean age of the participants at baseline was about 60-65 years (ESM Table 1) and about half were older than 65 years, the positive findings of these cardiovascular outcome trials appear to be relevant for drug selection in older patients with established CVD. Both empagliflozin [85] and liraglutide [87] were associated with an impressive reduction in cardiovascular death and all-cause mortality, which led to a change in the labelling of the drugs by the FDA and the European Medicines Agency (EMA). The number needed to treat to prevent one cardiovascular death was only 46 and 77 for empagliflozin and liraglutide, respectively, over 3 years. Hospitalisation owing to heart failure was only reduced by SGLT-2 inhibitors, which is relevant with regard to the high prevalence of heart failure in older people with type 2 diabetes. Interestingly, a decline in renal events was found with empagliflozin, canagliflozin and liraglutide when used in patients with long-standing type 2 diabetes and a history of CVD. Important renal events were decreased by all three drugs; however, a significant reduction of doubling of serum creatinine was only achieved by empagliflozin [85]. Overall mortality, hospitalisation owing 
to heart failure and incidence or worsening of nephropathy were also significantly reduced by empagliflozin vs placebo in patients aged $65-75$ years and $>75$ years at baseline [90-92]. Since participants in the cardiovascular outcome trials were selected based on the presence of established CVD, it is unknown whether SGLT-2 inhibitors and GLP-1 receptor agonists may also have beneficial effects on the heart and kidney in very early stages of the disease.

Subgroup analyses of different age groups $(<60$ years and $\geq 60$ years) from cardiovascular outcome trials with significant effects on the primary outcome (MACE, myocardial infarction or stroke) are summarised in Table 3. Interestingly, among older participants, substantial effects on three-point MACE were seen with empagliflozin, canagliflozin and exenatide, while liraglutide and semaglutide did not appear to confer any additional benefit. This effect observed with empagliflozin may be owing to the beneficial effect of this drug on heart failure, which is more common in older age [93].

Thiazolidinediones The use of thiazolidinediones, including pioglitazone, has declined drastically in recent years (from $28.5 \%$ in 2016 to $5.6 \%$ in 2013 in a population of 1.66 million patients with type 2 diabetes in the USA [40]), because of safety issues (increase in heart failure and bone fractures) and the availability of newer glucose-lowering drugs. Pioglitazone may be an option in carefully selected patients with diabetes [94] with previous stroke or transient ischaemic attack (TIA); in the Insulin Resistance Intervention after Stroke (IRIS) study, participants without diabetes but with insulin resistance and previous stroke or TIA showed a significant reduction in a subsequent stroke by $24 \%$ [95] and acute coronary syndrome by $29 \%$ [96] when pioglitazone was added to other cardiovascular-protective drugs. These data are in line with the significant reduction in repeat stroke by $48 \%$ in the Prospective Pioglitazone Clinical Trial in Macrovascular Events (PROactive), when individuals with diabetes and previous stroke were randomised to pioglitazone instead of placebo [97].

Glucose-lowering treatment in frail patients Very little is known about the effect and risk of glucose-lowering treatment in frail patients with type 2 diabetes. Recently, two different glucose-lowering treatment strategies were compared in vulnerable (moderately ill and/or frail) patients

Table 3 Results of subgroup analyses of cardiovascular outcome trials with significant effects in primary outcome

\begin{tabular}{|c|c|c|c|c|c|c|c|c|}
\hline \multirow[t]{2}{*}{ Trial } & \multirow[t]{2}{*}{$\begin{array}{l}\text { Glucose-lowering } \\
\text { agent }\end{array}$} & \multirow[t]{2}{*}{ Primary outcome } & \multirow[t]{2}{*}{ Age group } & \multirow[t]{2}{*}{$n$} & \multicolumn{2}{|c|}{$\begin{array}{l}\text { Percentage of participants } \\
\text { with event }\end{array}$} & \multirow[t]{2}{*}{ HR $(95 \%$ CI) } & \multirow[t]{2}{*}{$\begin{array}{l}p \text { value for } \\
\text { interaction }\end{array}$} \\
\hline & & & & & $\begin{array}{l}\text { Tested glucose- } \\
\text { lowering agent }\end{array}$ & Placebo & & \\
\hline \multirow[t]{3}{*}{ EMPA-REG [85] } & \multirow[t]{3}{*}{ Empagliflozin } & \multirow[t]{3}{*}{ Three-point MACE } & All ages & 7020 & 10.5 & 12.1 & $0.86(0.74,0.99)$ & \\
\hline & & & $<65$ years & 3893 & 9.7 & 9.3 & $1.04(0.84,1.29)$ & \\
\hline & & & $\geq 65$ years & 3127 & 11.4 & 15.5 & $0.71(0.59,0.87)$ & 0.01 \\
\hline \multirow[t]{3}{*}{ LEADER [87] } & \multirow[t]{3}{*}{ Liraglutide } & \multirow[t]{3}{*}{ Three -point MACE } & All ages & 9340 & 13.0 & 14.9 & $0.87(0.78,0.97)$ & \\
\hline & & & $<60$ years & 2321 & 11.7 & 14.8 & $0.78(0.62,0.97)$ & \\
\hline & & & $\geq 60$ years & 7019 & 13.5 & 14.9 & $0.90(0.79,1.02)$ & 0.27 \\
\hline \multirow[t]{3}{*}{ IRIS [94] } & \multirow[t]{3}{*}{ Pioglitazone } & \multirow[t]{3}{*}{ MI or stroke } & All ages & 3876 & 9.0 & 11.8 & $0.76(0.62,0.93)$ & \\
\hline & & & $<65$ years & 2168 & 7.5 & 10.2 & $0.73(0.55,0.97)$ & \\
\hline & & & $\geq 65$ years & 1708 & 10.9 & 13.8 & $0.79(0.60,1.03)$ & 0.72 \\
\hline \multirow[t]{3}{*}{ CANVAS [89] } & \multirow[t]{3}{*}{ Canagliflozin } & \multirow[t]{3}{*}{ Three -point MACE } & All ages & 10,142 & NR & NR & $0.86(0.75,0.97)$ & \\
\hline & & & $<65$ years & & NR & NR & $0.91(0.76,1.10)$ & \\
\hline & & & $\geq 65$ years & & NR & NR & $0.80(0.62,0.97)$ & 0.26 \\
\hline \multirow[t]{3}{*}{ SUSTAIN [86] } & \multirow[t]{3}{*}{ Semaglutide } & \multirow[t]{3}{*}{ Three -point MACE } & All ages & 3297 & 6.6 & 8.9 & $0.74(0.58,0.95)$ & \\
\hline & & & $<65$ years & 1699 & 6.2 & 8.3 & $0.74(0.52,1.05)$ & \\
\hline & & & $\geq 65$ years & 1598 & 6.9 & 9.4 & $0.72(0.51,1.02)$ & 0.95 \\
\hline \multirow[t]{3}{*}{ EXSCEL [81] } & \multirow[t]{3}{*}{ Exenatide } & \multirow[t]{3}{*}{ Three -point MACE } & All ages & 14,752 & 11.4 & 12.2 & $0.91(0.83,1.00)$ & \\
\hline & & & $<65$ years & 8813 & 9.4 & 8.9 & $1.05(0.92,1.21)$ & \\
\hline & & & $\geq 65$ years & 5939 & 14.4 & 17.2 & $0.80(0.71,0.91)$ & 0.005 \\
\hline
\end{tabular}

CANVAS, Canagliflozin Cardiovascular Assessment Study; EMPA-REG, Cardiovascular Outcome Event Trial in Type 2 Diabetes Mellitus; EXSCEL, Exenatide Study of Cardiovascular Event Lowering; IRIS, Insulin Resistance Intervention after Stroke; LEADER, Liraglutide Effect and Action in Diabetes: Evaluation of Cardiovascular Outcome Results; MI, myocardial infarction; NR, not reported; SUSTAIN, Trial to Evaluate Cardiovascular and Other Long-Term Outcomes with Semaglutide in Subjects with Type 2 Diabetes 


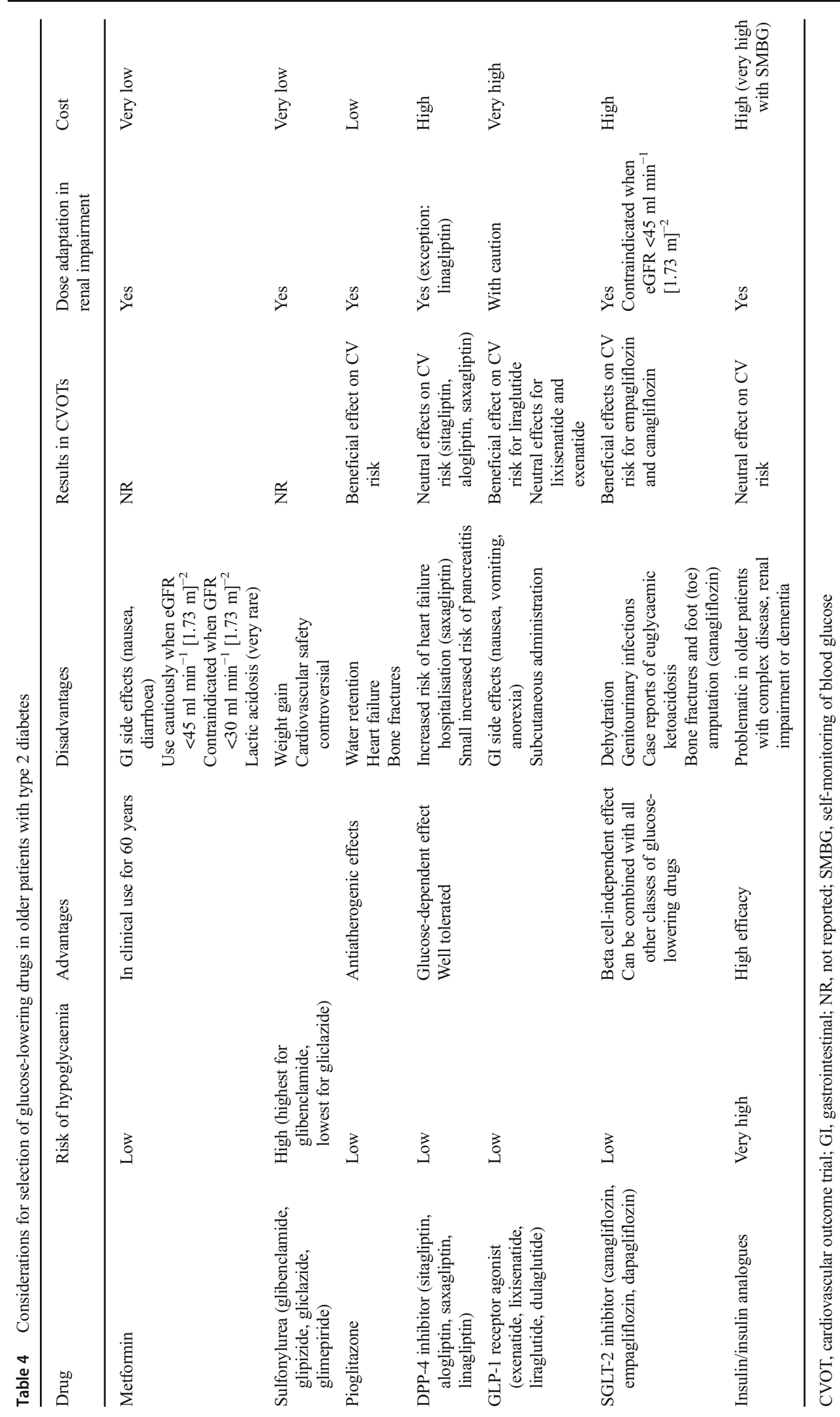


aged $\geq 65$ years with type 2 diabetes whose individual $\mathrm{HbA}_{1 \mathrm{c}}$ targets were not met with diet/exercise and/or oral antihyperglycaemic medications [98]. Both the glucosedependent strategy (a GLP-1 receptor agonist plus a non-sulfonylurea oral glucose-lowering drug) and the glucose-independent strategy (insulin glargine plus a sulfonylurea) reduced $\mathrm{HbA}_{1 \mathrm{c}}$ similarly, by $12.0 \mathrm{mmol} / \mathrm{mol}$ (1.1\%) from baseline to $55.2 \mathrm{mmol} / \mathrm{mol}(7.2 \%)$. Incidences of total, documented symptomatic, and asymptomatic hypoglycaemic events were significantly lower in patients treated with the glucose-dependent strategy vs the glucose-independent strategy $(10.2 \%$ vs $53.8 \%, 5.1 \%$ vs $36.6 \%, 8.2 \%$ vs $32.3 \%$, respectively; $p<0.001$ for each), indicating that a glucose-dependent strategy is preferable in the treatment of frail patients with diabetes.

Adverse effects Considerations for the selection of glucoselowering agents in the treatment of older people with type 2 diabetes are summarised in Table 4. Detailed information is given for each drug class, including risk for hypoglycaemia, advantages, disadvantages, results in cardiovascular outcome trials, dose adaptation in renal impairment and costs. In terms of adverse effects, gastrointestinal side effects are not uncommon with the use of metformin and GLP-1 receptor agonists and a very small risk of pancreatitis may exist for the use of DPP-4 inhibitors. Meanwhile, bone fractures have been reported for pioglitazone and canagliflozin, and mycotic genital infections are seen in about $5-10 \%$ of patients (more so in women than men) using SGLT-2 inhibitors. Recently, a small increased risk of foot amputation was also reported for canagliflozin [89]. Euglycaemic diabetic ketoacidosis may occur when older people with severe insulin deficiency receive SGLT-2 inhibitors, or when it is triggered, for example, by reductions in insulin dosage, low energy and fluid intake, intercurrent illness or alcohol. Remarkably, the well-monitored participants in the Empagliflozin Cardiovascular Outcome Event Trial in Type 2 Diabetes Mellitus (EMPA-REG Outcome) [85] and Canagliflozin Cardiovascular Assessment Study (CANVAS) [89] did not show any increase in diabetic ketoacidosis following intervention. Unfortunately, the relatively high costs of modern glucose-lowering drugs are an important limitation for their use in countries with a limited economy.

\section{Summary}

\section{Background}

The global prevalence of diabetes is increasing, with the largest age-specific rise predicted amongst people between $60-79$ years old

About one-third to one-quarter of those with diabetes in the USA, Brazil and China are $>65$ years old

In older adults with diabetes, and multiple serious comorbidities and functional limitations, the harm of intensive glycaemic control and severe hypoglycaemia likely exceeds the benefits

\section{How should we individualise treatment strategies in older patients with diabetes?}

A careful individual approach is required, whereby the health status, presence/absence of complications and life expectancy are taken into account

In 11 cardiovascular outcome trials, in which $\sim 50 \%$ of individuals were $>65$ years:

- Newer glucose-lowering drugs (pioglitazone, empagliflozin, liraglutide, semaglutide, canagliflozin) were associated with a significant reduction in three-point MACE, compared with placebo

- Insulin glargine, saxagliptin, alogliptin, sitagliptin, lixisenatide and exenatide showed safety but no change in cardiovascular mortality and morbidity, compared with placebo

- Incidence/worsening of nephropathy were significantly reduced by empagliflozin vs placebo in those with diabetes aged $65-75$ years and $>75$ years at baseline

Since $\sim 50 \%$ of patients in the cardiovascular outcome trials were $>65$ years, the observed cardio and nephroprotection may be relevant for drug selection in older patients with established cardiovascular disease 


\section{Future research}

In the next 30 years, older adults are predicted to make up the majority of those with type 2 diabetes. Thus, extensive research efforts are required, in particular for patients with a long life expectancy. A diabetes control and complications trial for older adults with diabetes stratified into participants with and without CVD would be very helpful to establish targets for $\mathrm{HbA}_{1 \mathrm{c}}$, $\mathrm{BP}$ and LDL-cholesterol levels for primary and secondary prevention of complications. Future research should aim to answer the many questions that remain in this field, such as when do some drugs induce more harm than benefit in vulnerable patients with complex disease? Further, it would be interesting to investigate whether newer glucose-lowering drugs (which recently demonstrated significant cardiovascular and renal benefit in those with a history of CVD) are also superior to the widely used more established drugs (e.g. metformin and sulfonylureas) in older individuals, or whether their benefit is only applicable to the prevention of severe hypoglycaemia in this age group, which is observed in about $1 \%$ of patients using sulfonylureas.

\section{Conclusion}

In summary, a carefully designed individual approach is needed for the treatment of older patients with type 2 diabetes, in which the health status, presence or absence of complications, and life expectancy should be taken into account. The heterogeneity of older people with diabetes must be considered. There is a need to individualise all therapeutic strategies based on specific factors that predict benefits and risks, including the functional and cognitive status of patients and the burden of comorbidities. Glucose-dependent drugs that do not induce hypoglycaemia are preferable because older patients with impaired kidney function are especially vulnerable to this adverse event. Since, in general, older people with diabetes but without complications now survive much longer than in our recent history, a multifactorial intervention to lower $\mathrm{HbA}_{1 \mathrm{c}}$ (to $53 \mathrm{mmol} / \mathrm{mol}$ [7.0\%]), BP (to <140/90 $\mathrm{mmHg}$ ) and lipids (i.e. use of statins) may be helpful to reduce the high risk of future development of heart failure, stroke, myocardial infarction and renal impairment. In 2017, the focus of the treatment of patients with type 2 diabetes is expanding to include the prevention of cardiovascular morbidity and mortality by use of specific glucose-lowering drugs with documented benefits in cardiovascular outcome trials. Empagliflozin and liraglutide have the best evidence to date among glucose-lowering agents for the reduction of cardiovascular death in patients with manifest CVD and type 2 diabetes. SGLT-2 inhibitors may be the preferred drug class in individuals with type 2 diabetes presenting with heart failure [99], which is much more common than previously believed [100]. Finally, early glycaemic control, avoidance of hypoglycaemia, and multifactorial cardiovascular risk factor-targeted interventions remain the cornerstones of cardiovascular and renal protection, even in older people with type 2 diabetes.

Acknowledgements Open access funding provided by Medical University of Vienna.

Duality of interest GS has served on global, European Union and national advisory board meetings of Amgen, AstraZeneca, Boehringer Ingelheim, Eli Lilly, Jansen, NovoNordisk, Sanofi-Aventis, Servier and Takeda. He has received honoraria for lectures for AstraZeneca, Boehringer Ingelheim, Eli Lilly, Jansen, NovoNordisk and Takeda. MHS-R has served on an advisory board for Boehringer Ingelheim and as a consultant for Novartis.

Contribution statement Both authors drafted and critically revised this article. Both authors approved the final version.

Open Access This article is distributed under the terms of the Creative Commons Attribution 4.0 International License (http:// creativecommons.org/licenses/by/4.0/), which permits unrestricted use, distribution, and reproduction in any medium, provided you give appropriate credit to the original author(s) and the source, provide a link to the Creative Commons license, and indicate if changes were made.

\section{References}

1. Ogurtsova K, da Rocha Fernandes JD, Huang Y et al (2017) IDF diabetes atlas: global estimates for the prevalence of diabetes for 2015 and 2040. Diabetes Res Clin Pract 128:40-50

2. Centers for Disease Control and Prevention (2017) National diabetes statistics report, 2017. Estimates of diabetes and its burden in the United States. Centers for Disease Control and Prevention, U.S. Dept of Health and Human Services, Atlanta, GA

3. de Almeida-Pititto B, Dias ML, de Moraes AC, Ferreira SR, Franco DR, Eliaschewitz FG (2015) Type 2 diabetes in Brazil: epidemiology and management. Diabetes Metab Syndr Obes 8: $17-28$

4. Yang W, Lu J, Weng J et al (2010) Prevalence of diabetes among men and women in China. N Engl J Med 362:1090-1101

5. Amati F, Dube JJ, Coen PM, Stefanovic-Racic M, Toledo FG, Goodpaster BH (2009) Physical inactivity and obesity underlie the insulin resistance of aging. Diabetes Care 32:1547-1549

6. Lee PG, Halter JB (2017) The pathophysiology of hyperglycemia in older adults: clinical considerations. Diabetes Care 40:444-452

7. Leslie RD, Kolb H, Schloot NC et al (2008) Diabetes classification: grey zones, sound and smoke: action LADA 1. Diabetes Metab Res Rev 24:511-519

8. Distiller LA (2014) Why do some patients with type 1 diabetes live so long? World J Diabetes 5:282-287

9. Tancredi M, Rosengren A, Svensson AM et al (2015) Excess mortality among persons with type 2 diabetes. N Engl J Med 373:1720-1732

10. Bauduceau B, Le Floch JP, Halimi S, Verny C, Doucet J, SFD/ SFGG Intergroup (2017) Cardiovascular complications over 5 years, and their association with survival in the GERODIAB co- 
hort of elderly French patients with type 2 diabetes. Diabetes Care. https://doi.org/10.2337/dc17-1437

11. Simo R, Ciudin A, Simo-Servat O, Hernandez C (2017) Cognitive impairment and dementia: a new emerging complication of type 2 diabetes - the diabetologist's perspective. Acta Diabetol 54:417424

12. Biessels GJ, Staekenborg S, Brunner E, Brayne C, Scheltens P (2006) Risk of dementia in diabetes mellitus: a systematic review. Lancet Neurol 5:64-74

13. Feil DG, Rajan M, Soroka O, Tseng CL, Miller DR, Pogach LM (2011) Risk of hypoglycemia in older veterans with dementia and cognitive impairment: implications for practice and policy. J Am Geriatr Soc 59:2263-2272

14. Crane PK, Walker R, Hubbard RA et al (2013) Glucose levels and risk of dementia. N Engl J Med 369:540-548

15. Ma L, Li Y (2017) Cognitive function and insulin resistance in elderly patients with type 2 diabetes. Neurol Res 39:259-263

16. Whitmer RA, Karter AJ, Yaffe K, Quesenberry CP Jr, Selby JV (2009) Hypoglycemic episodes and risk of dementia in older patients with type 2 diabetes mellitus. JAMA 301:1565-1572

17. Feinkohl I, Aung PP, Keller M et al (2014) Severe hypoglycemia and cognitive decline in older people with type 2 diabetes: the Edinburgh type 2 diabetes study. Diabetes Care 37:507-515

18. Munshi MN (2017) Cognitive dysfunction in older adults with diabetes: what a clinician needs to know. Diabetes Care 40:461467

19. Hubbard RE, Andrew MK, Fallah N, Rockwood K (2010) Comparison of the prognostic importance of diagnosed diabetes, co-morbidity and frailty in older people. Diabet Med 27:603-606

20. Kalinkovich A, Livshits G (2017) Sarcopenic obesity or obese sarcopenia: a cross talk between age-associated adipose tissue and skeletal muscle inflammation as a main mechanism of the pathogenesis. Ageing Res Rev 35:200-221

21. Kalyani RR, Tian J, Xue QL et al (2012) Hyperglycemia and incidence of frailty and lower extremity mobility limitations in older women. J Am Geriatr Soc 60:1701-1707

22. Wilhelm-Leen ER, Hall YN, Tamura MK, Chertow GM (2009) Frailty and chronic kidney disease: the Third National Health and Nutrition Evaluation Survey. Am J Med 122:664-671

23. Sinclair A, Dunning T, Rodriguez-Manas L (2015) Diabetes in older people: new insights and remaining challenges. Lancet Diabetes Endocrinol 3:275-285

24. Gregg EW, Li Y, Wang J et al (2014) Changes in diabetes-related complications in the United States, 1990-2010. N Engl J Med 370: 1514-1523

25. Carstensen B, Kristensen JK, Ottosen P, Borch-Johnsen K, Steering Group of the National Diabetes Register (2008) The Danish National Diabetes Register: trends in incidence, prevalence and mortality. Diabetologia 51:2187-2196

26. Gregg EW, Cheng YJ, Saydah S et al (2012) Trends in death rates among U.S. adults with and without diabetes between 1997 and 2006: findings from the National Health Interview Survey. Diabetes Care 35:1252-1257

27. Lind M, Garcia-Rodriguez LA, Booth GL et al (2013) Mortality trends in patients with and without diabetes in Ontario, Canada and the UK from 1996 to 2009: a population-based study. Diabetologia 56:2601-2608

28. Harding JL, Shaw JE, Peeters A, Davidson S, Magliano DJ (2016) Age-specific trends from 2000-2011 in all-cause and causespecific mortality in type 1 and type 2 diabetes: a cohort study of more than one million people. Diabetes Care 39:1018-1026

29. Alegre-Diaz J, Herrington W, Lopez-Cervantes M et al (2016) Diabetes and cause-specific mortality in Mexico City. N Engl J Med 375:1961-1971
30. Budnitz DS, Lovegrove MC, Shehab N, Richards CL (2011) Emergency hospitalizations for adverse drug events in older Americans. N Engl J Med 365:2002-2012

31. Thorpe CT, Gellad WF, Good CB et al (2015) Tight glycemic control and use of hypoglycemic medications in older veterans with type 2 diabetes and comorbid dementia. Diabetes Care 38: 588-595

32. Lipska KJ, Ross JS, Miao Y, Shah ND, Lee SJ, Steinman MA (2015) Potential overtreatment of diabetes mellitus in older adults with tight glycemic control. JAMA Intern Med 175:356-362

33. Meneilly GS, Berard LD, Cheng AYY et al (2017) Insights into the current management of older adults with type 2 diabetes in the Ontario primary care setting. Can J Diabetes. https://doi.org/10. 1016/j.jcjd.2017.03.003

34. Bruce DG, Davis WA, Casey GP et al (2009) Severe hypoglycaemia and cognitive impairment in older patients with diabetes: the Fremantle Diabetes Study. Diabetologia 52:18081815

35. Kirkman MS, Briscoe VJ, Clark N et al (2012) Diabetes in older adults. Diabetes Care 35:2650-2664

36. McCoy RG, Lipska KJ, Yao X, Ross JS, Montori VM, Shah ND (2016) Intensive treatment and severe hypoglycemia among adults with type 2 diabetes. JAMA Intern Med 176:969-978

37. Schernthaner G, Barnett AH, Betteridge DJ et al (2010) Is the ADA/EASD algorithm for the management of type 2 diabetes (January 2009) based on evidence or opinion? A critical analysis. Diabetologia 53:1258-1269

38. Ismail-Beigi F, Moghissi E, Tiktin M, Hirsch IB, Inzucchi SE, Genuth S (2011) Individualizing glycemic targets in type 2 diabetes mellitus: implications of recent clinical trials. Ann Intern Med 154:554-559

39. Inzucchi SE, Bergenstal RM, Buse JB et al (2012) Management of hyperglycaemia in type 2 diabetes: a patient-centered approach. Position statement of the American Diabetes Association (ADA) and the European Association for the Study of Diabetes (EASD). Diabetologia 55:1577-1596

40. Lipska KJ, Yao X, Herrin J et al (2017) Trends in drug utilization, glycemic control, and rates of severe hypoglycemia, 2006-2013. Diabetes Care 40:468-475

41. Goto A, Goto M, Terauchi Y, Yamaguchi N, Noda M (2016) Association between severe hypoglycemia and cardiovascular disease risk in Japanese patients with type 2 diabetes. J Am Heart Assoc 5:e002875

42. Munshi MN, Segal AR, Suhl E et al (2011) Frequent hypoglycemia among elderly patients with poor glycemic control. Arch Intern Med 171:362-364

43. Huang ES, Liu JY, Moffet HH, John PM, Karter AJ (2011) Glycemic control, complications, and death in older diabetic patients: the Diabetes and Aging Study. Diabetes Care 34:13291336

44. Schernthaner G, Ritz E, Schernthaner GH (2010) Strict glycaemic control in diabetic patients with CKD or ESRD: beneficial or deadly? Nephrol Dial Transplant 25:2044-2047

45. Avogaro A, Schernthaner G (2013) Achieving glycemic control in patients with type 2 diabetes and renal impairment. Acta Diabetol 50:283-291

46. Perkovic V, Heerspink HL, Chalmers J et al (2013) Intensive glucose control improves kidney outcomes in patients with type 2 diabetes. Kidney Int 83:517-523

47. Zoungas S, Patel A, Chalmers J et al (2010) Severe hypoglycemia and risks of vascular events and death. N Engl J Med 363:1410 1418

48. Clemens KK, Liu K, Shariff S, Schernthaner G, Tangri N, Garg AX (2016) Secular trends in antihyperglycaemic medication prescriptions in older adults with diabetes and chronic kidney disease: 2004-2013. Diabetes Obes Metab 18:607-614 
49. Schernthaner G, Schernthaner-Reiter MH (2015) Therapy: risk of metformin use in patients with T2DM and advanced CKD. Nat Rev Endocrinol 11:697-699

50. Hung SC, Chang YK, Liu JS et al (2015) Metformin use and mortality in patients with advanced chronic kidney disease: national, retrospective, observational, cohort study. Lancet Diabetes Endocrinol 3:605-614

51. van Dalem J, Brouwers MC, Stehouwer CD et al (2016) Risk of hypoglycaemia in users of sulphonylureas compared with metformin in relation to renal function and sulphonylurea metabolite group: population based cohort study. BMJ 354:i3625

52. Cooper ME, Perkovic V, McGill JB et al (2015) Kidney disease end points in a pooled analysis of individual patient-level data from a large clinical trials program of the dipeptidyl peptidase 4 inhibitor linagliptin in type 2 diabetes. Am J Kidney Dis 66:441449

53. Nathan DM, Buse JB, Davidson MB et al (2009) Medical management of hyperglycaemia in type 2 diabetes mellitus: a consensus algorithm for the initiation and adjustment of therapy: a consensus statement from the American Diabetes Association and the European Association for the Study of Diabetes. Diabetologia 52: $17-30$

54. Action to Control Cardiovascular Risk in Diabetes Study Group, Gerstein HC, Miller ME et al (2008) Effects of intensive glucose lowering in type 2 diabetes. N Engl J Med 358:2545-2559

55. ADVANCE Collaborative Group, Patel A, MacMahon $\mathrm{S}$ et al (2008) Intensive blood glucose control and vascular outcomes in patients with type 2 diabetes. N Engl J Med 358:2560-2572

56. Duckworth W, Abraira C, Moritz T et al (2009) Glucose control and vascular complications in veterans with type 2 diabetes. $\mathrm{N}$ Engl J Med 360:129-139

57. Frier BM, Schernthaner G, Heller SR (2011) Hypoglycemia and cardiovascular risks. Diabetes Care 34(Suppl 2):S132-S137

58. Bonds DE, Miller ME, Bergenstal RM et al (2010) The association between symptomatic, severe hypoglycaemia and mortality in type 2 diabetes: retrospective epidemiological analysis of the ACCORD study. BMJ 340:b4909

59. Sinclair AJ, Paolisso G, Castro M et al (2011) European Diabetes Working Party for Older People 2011 clinical guidelines for type 2 diabetes mellitus. Executive summary. Diabetes Metab 37(Suppl 3):S27-S38

60. International Diabetes Federation (2013) IDF global guideline for managing older people with type 2 diabetes. International Diabetes Federation, Brussels

61. Sinclair A, Morley JE, Rodriguez-Manas L et al (2012) Diabetes mellitus in older people: position statement on behalf of the International Association of Gerontology and Geriatrics (IAGG), the European Diabetes Working Party for Older People (EDWPOP), and the International Task Force of Experts in Diabetes. J Am Med Dir Assoc 13:497-502

62. Canadian Diabetes Association Clinical Practice Guidelines Expert Committee, Meneilly GS, Knip A, Tessier D (2013) Diabetes in the elderly. Can J Diabetes 37(Suppl 1):S184-S190

63. Palta P, Huang ES, Kalyani RR, Golden SH, Yeh HC (2017) Hemoglobin $\mathrm{A}_{1 \mathrm{c}}$ and mortality in older adults with and without diabetes: results from the National Health and Nutrition Examination Surveys (1988-2011). Diabetes Care 40:453-460

64. Hamada S, Gulliford MC (2016) Mortality in individuals aged 80 and older with type 2 diabetes mellitus in relation to glycosylated hemoglobin, blood pressure, and total cholesterol. J Am Geriatr Soc 64:1425-1431

65. American Diabetes Association (2016) 8. Cardiovascular disease and risk management. Diabetes Care 39(Suppl 1):S60-S71

66. American Diabetes Association (2017) 9. Cardiovascular disease and risk management. Diabetes Care 40(Supp11):S75-S87
67. Inzucchi SE, Bergenstal RM, Buse JB et al (2015) Management of hyperglycaemia in type 2 diabetes, 2015: a patient-centred approach. Update to a position statement of the American Diabetes Association and the European Association for the Study of Diabetes. Diabetologia 58:429-442

68. Schernthaner G, Schernthaner GH (2007) Metformin - from devil to angel. In: Mogensen CE (ed) Pharmacotherapy of diabetes. New developments: improving life and prognosis for diabetic patients. Springer US, Boston, pp 77-86

69. Bailey CJ, Turner RC (1996) Metformin. N Engl J Med 334:574 579

70. Schernthaner G, Matthews DR, Charbonnel B, Hanefeld M, Brunetti P, Quartet Study Group (2004) Efficacy and safety of pioglitazone versus metformin in patients with type 2 diabetes mellitus: a double-blind, randomized trial. J Clin Endocrinol Metab 89:6068-6076

71. Kahn SE, Haffner SM, Heise MA et al (2006) Glycemic durability of rosiglitazone, metformin, or glyburide monotherapy. N Engl J Med 355:2427-2443

72. Schernthaner G, Grimaldi A, Di Mario U et al (2004) GUIDE study: double-blind comparison of once-daily gliclazide MR and glimepiride in type 2 diabetic patients. Eur J Clin Investig 34:535542

73. Simpson SH, Lee J, Choi S, Vandermeer B, Abdelmoneim AS, Featherstone TR (2015) Mortality risk among sulfonylureas: a systematic review and network meta-analysis. Lancet Diabetes Endocrinol 3:43-51

74. Barnett AH, Huisman H, Jones R, von Eynatten M, Patel S, Woerle HJ (2013) Linagliptin for patients aged 70 years or older with type 2 diabetes inadequately controlled with common antidiabetes treatments: a randomised, double-blind, placebocontrolled trial. Lancet 382:1413-1423

75. Schernthaner G, Duran-Garcia S, Hanefeld M et al (2015) Efficacy and tolerability of saxagliptin compared with glimepiride in elderly patients with type 2 diabetes: a randomized, controlled study (GENERATION). Diabetes Obes Metab 17:630-638

76. Strain WD, Lukashevich V, Kothny W, Hoellinger MJ, Paldanius PM (2013) Individualised treatment targets for elderly patients with type 2 diabetes using vildagliptin add-on or lone therapy (INTERVAL): a 24 week, randomised, double-blind, placebocontrolled study. Lancet 382:409-416

77. Zhong VW, Juhaeri J, Cole SR et al (2017) Incidence and trends in hypoglycemia hospitalization in adults with type 1 and type 2 diabetes in England, 1998-2013: a retrospective cohort study. Diabetes Care 40:1651-1660

78. Scirica BM, Bhatt DL, Braunwald E et al (2013) Saxagliptin and cardiovascular outcomes in patients with type 2 diabetes mellitus. N Engl J Med 369:1317-1326

79. White WB, Cannon CP, Heller SR et al (2013) Alogliptin after acute coronary syndrome in patients with type 2 diabetes. $\mathrm{N}$ Engl $\mathrm{J}$ Med 369:1327-1335

80. Green JB, Bethel MA, Armstrong PW et al (2015) Effect of sitagliptin on cardiovascular outcomes in type 2 diabetes. $\mathrm{N}$ Engl J Med 373:232-242

81. Holman RR, Bethel MA, Mentz RJ et al (2017) Effects of onceweekly exenatide on cardiovascular outcomes in type 2 diabetes. N Engl J Med 377:1228-1239

82. Schernthaner G, Cahn A, Raz I (2016) Is the use of DPP-4 inhibitors associated with an increased risk for heart failure? Lessons from EXAMINE, SAVOR-TIMI 53, and TECOS. Diabetes Care 39(Suppl 2):S210-S218

83. Dormandy JA, Charbonnel B, Eckland DJ et al (2005) Secondary prevention of macrovascular events in patients with type 2 diabetes in the PROactive Study (PROspective pioglitAzone Clinical 
Trial In macroVascular Events): a randomised controlled trial. Lancet 366:1279-1289

84. Origin Trial Investigators, Gerstein HC, Bosch J et al (2012) Basal insulin and cardiovascular and other outcomes in dysglycemia. $\mathrm{N}$ Engl J Med 367:319-328

85. Zinman B, Wanner C, Lachin JM et al (2015) Empagliflozin, cardiovascular outcomes, and mortality in type 2 diabetes. $\mathrm{N}$ Engl J Med 373:2117-2128

86. Marso SP, Bain SC, Consoli A et al (2016) Semaglutide and cardiovascular outcomes in patients with type 2 diabetes. N Engl J Med 375:1834-1844

87. Marso SP, Daniels GH, Brown-Frandsen K et al (2016) Liraglutide and cardiovascular outcomes in type 2 diabetes. $\mathrm{N}$ Engl J Med 375:311-322

88. Pfeffer MA, Claggett B, Diaz R et al (2015) Lixisenatide in patients with type 2 diabetes and acute coronary syndrome. N Engl J Med 373:2247-2257

89. Neal B, Perkovic V, Mahaffey KW et al (2017) Canagliflozin and cardiovascular and renal events in type 2 diabetes. N Engl J Med 377:644-657

90. Monteiro P, Schaper N, Clark D et al (2016) Effect of empagliflozin on heart failure outcomes in subgroups by age: results from EMPA-REG OUTCOME. Diabetologia 59:S534 (abstract)

91. Toural E, Ridderstrale M, Fitchett D et al (2016) Effect of empagliflozin on cardiovascular death in subgroups by age: results from EMPA-REG OUTCOME. Diabetologia 59:S539-S540 abstract

92. von Eynatten M, Bergenstal RM, Calabro P, Mattheus M, Lachin JM, Wanner C (2016) Effect of empagliflozin on nephropathy in subgroups by age: results from EMPA-REG OUTCOME. Diabetologia 59:S483 (abstract)

93. Nichols GA, Hillier TA, Erbey JR, Brown JB (2001) Congestive heart failure in type 2 diabetes: prevalence, incidence, and risk factors. Diabetes Care 24:1614-1619

94. Schernthaner G, Currie CJ, Schernthaner GH (2013) Do we still need pioglitazone for the treatment of type 2 diabetes? A riskbenefit critique in 2013. Diabetes Care 36(Suppl 2):S155-S161

95. Kernan WN, Viscoli CM, Furie KL et al (2016) Pioglitazone after ischemic stroke or transient ischemic attack. N Engl J Med 374: 1321-1331

96. Young LH, Viscoli CM, Curtis JP et al (2017) Cardiac outcomes after ischemic stroke or transient ischemic attack: effects of pioglitazone in patients with insulin resistance without diabetes mellitus. Circulation 135:1882-1893

97. Wilcox R, Bousser MG, Betteridge DJ et al (2007) Effects of pioglitazone in patients with type 2 diabetes with or without previous stroke: results from PROactive (PROspective pioglitAzone Clinical Trial In macroVascular Events 04). Stroke 38:865-873

98. Heller SR, Pratley RE, Sinclair A et al (2018) Glycaemic outcomes of an Individualized treatMent aPproach for oldER vulnerable patIents: A randomized, controlled stUdy in type 2 diabetes Mellitus (IMPERIUM). Diabetes Obes Metab 20:148-156

99. Fitchett DH, Udell JA, Inzucchi SE (2017) Heart failure outcomes in clinical trials of glucose-lowering agents in patients with diabetes. Eur J Heart Fail 19:43-53

100. McMurray JJ, Gerstein HC, Holman RR, Pfeffer MA (2014) Heart failure: a cardiovascular outcome in diabetes that can no longer be ignored. Lancet Diabetes Endocrinol 2:843-851 